\title{
FUNGSI AFEKTIF KELUARGA DAN FUNGSI SOSIALISASI KELUARGA DENGAN PERILAKU SEKSUAL REMAJA
}

\author{
Immanuel Chandra Supit Pattiruhu \\ Sefti Rompas \\ Valen Simak \\ Program Studi Ilmu Keperawatan Fakultas Kedokteran \\ Universitas Sam Ratulangi \\ Email : chandrapatiruhu@gmail.com
}

\begin{abstract}
Sexual behavior is risky behavior that aims to attract the attention of the opposite sex which involves touching physical limbs between men and women who have reached intimate relationships. Family functions that are not good can affect adolescent sexual behavior. Therefore, the affective function of the family and family socialization functions play a special role in adolescent growth and development. The aim of this research was to determine the corelation between family affective function and family socialization function with adolescent sexual behavior in SMK Negeri 1 Manado. The research design used descriptive analysis with a cross sectional study approach. This research involved312 respondents obtained by using the Simple Random Sampling technique. The results of the statistical test using Chi-square test at a significance level of 95\%, obtained a significant value $\rho=0,000<\alpha(0,05)$ for affective function of family with sexual behavior in adolescent and $\rho=0,000<\alpha(0,05)$ for socialization function of family with sexual behavior in adolescent. Conclusion there is a corelation between family affective function with adolescent sexual behavior and there is a corelation between family socialization function with adolescent sexual behavior.
\end{abstract}

Keywords : Affective Function, Function of Socialization, Adolescent, Sexual Behavior

\begin{abstract}
Abstrak : Perilaku seksual merupakan perilaku beresiko yang bertujuan untuk menarik perhatian lawan jenis yang melibatkan sentuhan secara fisik anggota badan antara pria dan wanita yang telah mencapai pada hubungan intim. Fungsi keluarga yang tidak baik dapat mempengaruhi perilaku seksual remaja. Oleh karena itu, fungsi afektif keluarga dan fungsi sosialisasi keluarga sangat berperan khusus dalam tumbuh kembang remaja. Tujuan untuk mengetahui hubungan fungsi afektif keluarga dan fungsi sosialisasi keluarga dengan perilaku seksual remaja di SMK Negeri 1 Manado. Desain penelitian yang digunakan yaitu Deskriptif Analitik dengan pendekatan Cross Sectional Study. Sampel berjumlah 312 responden yang didapat dengan menggunakan tehnik Simple Random Sampling. Hasil penelitian uji statistic menggunakan uji Chi-square pada tingkat kemaknaan 95\%, didapatkan nilai signifikan $\rho=$ $0,000<\alpha(0,05)$ untuk Fungsi Afektif keluarga dengan perilaku seksual remaja dan $\rho=0,000$ $<\alpha(0,05)$ untuk Fungsi Sosialisasi keluarga dengan perilaku seksual remaja. Kesimpulan ada hubungan antara fungsi afektif keluarga dengan perilaku seksual remaja dan ada hubungan antara fungsi sosialisasi keluarga dengan perilaku seksual remaja.
\end{abstract}

Kata kunci : Fungsi Afektif, Fungsi Sosialisasi, Perilaku Seksual, Remaja 
e-journal Keperawatan(e-Kp) Volume 7 Nomor 2, Agustus 2019

\section{PENDAHULUAN}

Masa remaja (adolescent) merupakan masa dimana terjadi transisi masa kanak-kanak menuju dewasa, biasanya antara usia 13 sampai 20 tahun (Aguma, dkk, 2014). Masa remaja berdasarkan umur di bedakan dalam 3 kelompok yaitu; Masa remaja awal 10-13 tahun, masa remaja tengah 14-16 tahun, masa remaja akhir 17-19 tahun (Sebayang, dkk, 2018). Data yang didapatkan di dunia diperkirakan kelompok remaja berjumlah 1,2 miliyar atau $18 \%$ dari jumlah penduduk dunia (kompas.com 2009). Badan Kependudukan dan Keluarga Berencana Nasional (2016) menyebutkan penduduk remaja berusia 10-24 tahun berjumlah 66,3 juta jiwa dari total penduduk Indonesia sebesar 258,7 juta sehingga satu di antara empat penduduk adalah remaja. Begitu juga dengan data Badan Pusat Statistik Kota Manado (2015) jumlah penduduk Kota Manado sebanyak 425.634 jiwa, dengan kelompok umur 1519 tahun sebanyak 38.879 jiwa dan kelompok umur 20-24 tahun sebanyak 45.402 jiwa.

Data hasil survey mengenai jumlah remaja memiliki arti bahwa jumlah remaja merupakan kelompok usia yang ditandai dengan percepatan perkembangan fisik biologis, mental, dan sosial (Aguma, dkk, 2014). Berbagai perkembangan dapat menimbulkan persoalan-persoalan yang kemungkinan dapat mengganggu perkembangan remaja tersebut, diantara persoalan tersebut yang dihadapi remaja adalah masalah kesehatan reproduksi yang semakin meningkat. Berbagai penyakit menular seksual (PMS) makin banyak terjadi pada remaja bahkan bentuk perilaku seksualpun makin sering dilakukan oleh para remaja (Taukhit, 2014). Penelitian yang dilakukan di Cina tahun 2009 menunjukkan bahwa $22,4 \%$ pemuda berusia 15-24 tahun pernah melakukan hubungan seksual pranikah. Hasil survei Survey Demografi Kesehatan Indonesia (SDKI) pada tahun 2012 juga menunjukkan bahwa sekitar 9,3\% atau sekitar 3,7 juta remaja menyatakan pernah melakukan hubungan seksual pranikah, sedangkan pada tahun 2007 hanya sekitar $7 \%$ atau sekitar 3 juta remaja. Sehingga selama periode tahun 2007 sampai 2012 terjadi peningkatan kasus remaja yang pernah melakukan hubungan seksual pranikah sebanyak 2,3\% (Arub, 2017).

Meningkatnya minat seks pada remaja dan kurangnya pengetahuan remaja tentang perilaku seks pranikah, ditambah dengan kurangnya keterbukaan keluarga dalam dalam membicarakan permasalahan seks menjadi salah satu faktor remaja terjerumus kedalam periaku seks pranikah (Arub, 2017). Hal ini sejalan dengan penelitian Saputri (2015) yang mengatakan Pengetahuan merupakan salah satu faktor yang menyebabkan perilaku seksual. Hal ini kemudian berpengaruh kepada pergaulan remaja dan akan diperburuk oleh pergaulan yang memberikan kebebasan tanpa kendali dari keluarga. Jika tanpa kendali dari keluarga dan pembentukan sikap dan tingkah laku oleh orang tua dan fungsi keluarga sebagai hal yang sangat penting tidak dilakukan dengan tepat terhadap remaja, maka pergaulan bebas remaja semakin mudah untuk dilakukan (Mellyanika, 2014).

Departemen Kesehatan Republik Indonesia sejak tahun 2003, pemerintah indonesia khususnya kementrian kesehatan telah mengembangkan model pelayanan 
kesehatan yang di sebut dengan Pelayanan Kesehatan Peduli Remaja (PKPR) sebagai upaya untuk menyelesaikan masalah perilaku seksual remaja. Pelayanan ini di koordinasi oleh program Generasi Berencara (GenRe) yang di selenggarakan Badan Kependudukan dan Keluarga Berencana (BKKBN) dengan pendekatan dua sisi yaitu kepada keluarga yang memiliki remaja dan kepada remaja itu sendiri. Berdasarkan upaya pemerintah melalui pendekatan tersebut maka dari itu Fungsi keluarga sangat di perlukan untuk membentuk perilaku seorang remaja (Mutmainnah, 2013).

Friedman (2010) mengidentifikasi lima fungsi dasar keluarga, yaitu fungsi afektif, fungsi sosialisasi, fungsi reproduksi, fungsi ekonomi dan fungsi perawatan keluarga. Dalam penelitian ini peneliti hanya memfokuskan pada fungsi afektif keluarga dan fungsi sosialisasi keluarga di karenakan fungsi afektif keluarga berkaitan dengan fungsi internal keluarga dan adanya perceraian, kenakalan remaja dan masalah lainnya yang sering timbul dalam keluarga di karenakan fungsi afektif keluarga yang tidak terpenuhi. Hal ini sejalan dengan penelitian yang di lakukan Mursafitri, dkk (2015) yang mengatakan ada hubungan antara fungsi afektif keluarga dengan perilaku kenakalan remaja. Sedangkan untuk fungsi sosialisasi keluarga karena jika di lihat dari karakteristik remaja, remaja masih dalam masa transisi sehingga dapat terpengaruh oleh berbagai hal khususnya pengaruh pergaulan teman sebaya (Santrock, 2007). Hal ini di dukung oleh penelitian yang di lakukan Pradhana (2016) yang mengatakan bahwa ada hubungan antara peran teman sebaya dengan perilaku seksual remaja.

Pemberian kasih sayang dalam keluarga, termasuk di dalam fungsi afektif keluarga yang merupakan fungsi internal keluarga yaitu perlindungan dan dukungan psikososial bagi para anggotanya. Adanya perceraian, kenakalan remaja dan masalah lainnya yang sering timbul dalam keluarga dikarenakan fungsi afektif keluarga yang tidak terpenuhi (Mursafitri, dkk, 2015). Hal ini di dukung juga oleh penelitian yang di lakukan Mellyanika (2014) yang mengatakan bahwa Perilaku seks remaja terjadi akibat dari tidak berfungsinya fungsi keluarga dalam hal ini Fungsi Afektif.

Fungsi sosialisasi keluarga tercermin dalam melakukan pembinaan sosialisasi pada anak, membentuk nilai dan norma yang di yakini anak, memberikan batasan perilaku yang boleh dan tidak boleh pada anak, meneruskan nilai-nilai budaya keluarga. Bagaimana keluarga produktif terhadap sosial dan bagaimana keluarga memperkenalkan anak dengan dunia luar dengan belajar disiplin, mengenal budaya dan norma melalui hubungan interaksi dalam keluarga sehingga mampu berperan dalam masyarakat (Arinda, 2014). Penelitian yang di lakukan Mellyanika (2014) mengatakan bahwa ada hubungan antara Fungsi sosialisasi keluarga dengan perilaku seksual pra nikah remaja dikarenakan ketidakberfungsiannya fungsi keluarga dalam hal ini fungsi sosialisasi keluarga.

Studi pendahuluan yang dilakukan sebelumnya oleh peneliti dengan mewawancarai 18 siswa di SMK Negeri 1 Manado tentang Fungsi Afektif Keluarga dan Fungsi Sosialisasi Keluarga Dengan Perilaku Seksual di mana mereka mengatakan pernah bolos dari sekolah, datang terlambat ke sekolah, pernah keluar kelas sebelum jam istirahat dan tidak mengikuti ibadah pada saat ibadah di laksanakan di sekolah dan di dapatkan 9 orang siswa yang memiliki fungsi afektif keluarga kurang baik dan 5 orang juga memiliki fungsi sosialisasi kurang baik, dan 4 orang lainnya memilki fungsi afektif keluarga dan fungsi sosialisasi keluarga yang baik. Untuk perilaku seksual 1 orang 
belum pernah pacaran dan 17 orang pernah pacaran dimana 6 orang pernah keluar malam tanpa di ketahui orang tua, 11 orang pernah pegangan tangan dan ciuman bibir dan pada pipi, 6 orang berpelukan dan didapatkan juga adanya kejadian beberapa siswi hamil diluar nikah dan di beri sanksi oleh pihak sekolah. Sehingga, berdasarkan hal diatas saya tertarik untuk melakukan penelitian mengenai "Hubungan Fungsi Afektif Keluarga Dan Fungsi Sosialisasi Keluarga Dengan Perilaku Seksual Remaja Di SMK Negeri 1 Manado".

\section{METODE PENELITIAN}

Penelitian ini termasuk dalam jenis penelitian kuantitatif dengan menganalisis gambaran hubungan antara kedua variabel yaitu variabel independen (Fungsi Afektif Keluarga dan Fungsi Sosialisasi Keluarga) dan variabel dependen (Perilaku Seksual Remaja). Penelitian ini menggunakan desain penelitian cross sectional. Penelitian ini dilaksanakan di SMK Negeri 1 Manado pada bulan Februari-Juni 2019. Populasi penelitian ini adalah seluruh kelas $X$ dan IX dengan jumlah 1410 . Pengambilan sampel menggunakan teknik Simple random sampling dengan rumus slovin maka didapatkan jumlah sampel 312 remaja. Instrumen penelitian yang digunakan untuk mengukur variabel Fungsi Afektif Keluarga menggunakan kuesioner yang digunakan sebelumnya oleh Leni, (2019). Kuesioner ini terdiri dari 10 pernyataan. $1=$ sangat tidak setuju, $2=$ tidak setuju, $3=$ setuju , 4= sangat setuju. Setelah lembar kuesioner diisi oleh responden, kemudian dilakukan penghitungan skor dengan cara menjumlahkan skor tiap pertanyaan. Untuk menentukan jenis fungsi afektif keluarga yang diterapkan oleh orang tua dilihat dari skor tertinggi.

Pengukuran Fungsi Sosialisasi Keluarga menggunakan kuesioner yang digunakan sebelumnya oleh Nurcholis
(2015) dengan kriteria skor $1=\mathrm{Ya}, 0=$ Tidak untuk favorable, dan sebaliknya untuk unfavorable. Pengukuran Perilaku Seksual Remaja menggunakan kuesioner yang di gunakan sebelumnya oleh Aguma dkk (2014) dengan kriteria skor, beresiko jika responden menjawab pertanyaan nomor $(4,7,9,12,13)$, dan tidak beresiko jika menjawab pertanyaan nomor $(1,2,3,5,6,8,10,11)$.

Pengolahan data yang diperoleh dari hasil penelitian ini diolah secara manual dengan mengelompokkan hasil wawancara dan observasi kemudian dilakukan penghitungan skor dan dianalisis menggunakan uji statistik melalui sistem komuterisasi dengan beberapa tahap yaitu editing, coding, cleaning, tabulating (Notoatmodjo, 2010). Analisa bivariat dalam penelitian ini yaitu untuk mengetahui hubungan Fungsi Afektif Keluarga dan Fungsi Sosialisasi Keluarga dengan Perilaku Seksual Remaja di SMK Negeri 1 Manado. Peneliti menggunakan uji statistic Chi Square dengan tingkat kemaknaan $95 \%(\alpha=0,05)$.

\section{HASIL dan PEMBAHASAN}

\section{Karakteristik Responden}

Tabel 1. Distribusi Responden Berdasarkan Jenis Kelamin

\begin{tabular}{ccc}
\hline Jenis Kelamin & $\mathbf{n}$ & $\mathbf{\%}$ \\
\hline Laki-laki & 183 & 58,7 \\
Perempuan & 129 & 41,3 \\
\hline Total & $\mathbf{3 1 2}$ & $\mathbf{1 0 0}$ \\
\hline
\end{tabular}

Sumber : Data Primer 2019

Berdasarkan Jenis kelamin, diperoleh mayoritas responden adalah berjenis kelamin laki-laki $(58,7 \%)$. Hasil penelitian ini sejalan dengan penelitian Mursafitri, dkk, (2015). Perekembangan seksual remaja perempuan biasanya mulai dari 12 tahun dan laki-laki 14 tahun, tetapi pada perkembangannya remaja laki-laki lebih aktif secara seksual dari pada remaja perempuan (Samsi, 2012). 
e-journal Keperawatan(e-Kp) Volume 7 Nomor 2, Agustus 2019

Tabel 2. Distribusi Responden Berdasarkan Usia

\begin{tabular}{ccc}
\hline Usia & $\mathbf{n}$ & $\mathbf{\%}$ \\
\hline 15 Tahun & 192 & 61,5 \\
16 Tahun & 103 & 33,0 \\
17 Tahun & 17 & 5,4 \\
\hline Total & $\mathbf{3 1 2}$ & $\mathbf{1 0 0}$ \\
\hline
\end{tabular}

Sumber : Data Primer 2019

Hasil penelitian menunjukkan bahwa mayoritas responden berusia 15 tahun $(61,5 \%)$. Masa remaja, menurut WHO (2014) berlangsung antara usia 10 sampai dengan 19 tahun, dan menurut Menteri Kesehatan RI Nomor 25 tahun 2014 remaja yaitu yang berusia 10 sampai 18 tahun (Depkes RI, 2015). Remaja merupakan fase "mencari jati diri" (Ali \& Asrori, 2017). Semakin bertambahnya usia seseorang maka semakin bertambah pula pola pikirnya. Sehingga, sangatlah penting perhatian yang diberikan orang tua karena hal itu yang akan membentuk kepribadian anak tersebut (Christinna, dkk, 2017).

\section{Analisa Univariat}

Tabel 3. Distribusi Responden Berdasarkan Fungsi Afektif Keluarga

\begin{tabular}{ccc}
\hline $\begin{array}{c}\text { Fungsi Afektif } \\
\text { Keluarga }\end{array}$ & $\mathbf{n}$ & \% \\
\hline Kurang Baik & 130 & 41,7 \\
Baik & 182 & 58,3 \\
\hline Total & $\mathbf{3 1 2}$ & $\mathbf{1 0 0}$ \\
\hline
\end{tabular}

Sumber : Data Primer 2019

Tabel 3 menunjukkan bahwa mayoritas responden mayoritas memiliki Fungsi afektif yang baik $(58,3 \%)$ Hasil penelitian ini sesuai dengan Gustiani dan Ungsianik (2016) menunjukkan dengan jumlah $59(51,8 \%)$ responden dalam kategori baik/adekuat, sedangkan 55 $(48,2 \%)$ dalam kategori fungsi keluarga kurang baik, fungsi afektif keluarga yang baik memiliki jumlah terbanyak yaitu 59 orang. Fungsi afektif keluarga adalah fungsi internal keluarga yang berguna untuk pemenuhan kebutuhan psikososial dan merupakan sumber energi yang menentukan kebahagiaan keluarga (Friedman, 2010). Menurut Gustiani dan Ungsianik (2016), pada masa remaja, remaja cenderung meniru orang lain dan memberikan elaborasi mengenai sifat afektif hubungan keluarga kemudian mengimplementasikan dalam kehidupan pribadinya. Oleh karena itu, fungsi afektif keluarga sangat berpengaruh terhadap kelangsung hidup seorang remaja dalam melakukan hubungan dengan orang lain.

Tabel 4. Distribusi Responden Berdasarkan Fungsi Sosialisasi Keluarga

\begin{tabular}{ccc}
\hline $\begin{array}{c}\text { Fungsi Sosialisasi } \\
\text { Keluarga }\end{array}$ & $\mathbf{n}$ & $\mathbf{\%}$ \\
\hline Kurang Baik & 116 & 37,2 \\
Baik & 196 & 62,8 \\
\hline Total & $\mathbf{3 1 2}$ & $\mathbf{1 0 0}$ \\
\hline
\end{tabular}

Sumber : Data Primer 2019

Berdasarkan hasil menunjukkan mayoritas responden memiliki Fungsi Sosialisasi Keluarga yang baik (62,8\%). Keluarga yang menanamkan sosialisasi yang baik akan menghasilkan fungsi sosial yang baik, dan sebaliknya keluarga yang menanamkan sosialisasi yang tidak baik akan menghasilkan fungsi sosial yang tidak baik pula bagi anak. Keluarga yang menanamkan sosialisasi dan mensosialisasikan kedisiplinan serta cinta kasih sayang, maka akan membuat anak merasa nyaman untuk bersosialisasi (Gultom \& Karyaningsih, 2015).

Tabel 5. Distribusi Responden Berdasarkan Perilaku Seksual Remaja

\begin{tabular}{ccc}
\hline Perilaku Seksual Remaja & n & \% \\
\hline Beresiko & 89 & 28,5 \\
Tidak Beresiko & 223 & 71,5 \\
\hline Total & $\mathbf{3 1 2}$ & $\mathbf{1 0 0}$ \\
\hline Sumber $:$ Data Primer 2019 & &
\end{tabular}

Hasil analisa menunjukkan mayoritas responden memiliki Perilaku Seksual tidak beresiko $(71,5 \%)$. 
Masa remaja merupakan masa ingin tahu terhadap masalah seksual sangat penting dalam pembentukan hubungan yang lebih matang dengan lawan jenis. matangnya fungsi-fungsi seksual maka timbul pula dorongan-dorongan dan keinginan-keinginan untuk pemuasan seksual. Bila ada kesempatan remaja melakukan sentuhan fisik, melanjutkan dengan menyentuh bagian sensitif sampai bercumbu dengan lawan jenis atau pasangan. Perilaku seksual tidak beresiko itu sendiri menurut Mc Kinley Health Center dalam Dewi (2012) antara lain : berbicara mengenai seks, berbagi fantasi, pijtan atau sentuhan, kecupan bibir dan pipi.

\section{Analisa Bivariat}

Tabel 6. Hubungan Fungsi Afektif Keluarga dengan Perilaku Seksual Remaja

\begin{tabular}{cccccccc}
\hline $\begin{array}{c}\text { Fungsi } \\
\text { Afektif } \\
\text { Keluarga }\end{array}$ & \multicolumn{3}{c}{ Perilaku Seksual } & \multirow{2}{*}{ Total } & \multirow{2}{*}{ P } \\
\cline { 2 - 5 } & Beresiko & \multicolumn{2}{c}{$\begin{array}{c}\text { Tidak } \\
\text { Beresiko }\end{array}$} & & & \\
\cline { 2 - 6 } & $\mathrm{n}$ & $\%$ & $\mathrm{n}$ & $\%$ & $\mathrm{n}$ & $\%$ & \\
\hline $\begin{array}{c}\text { Kurang } \\
\text { Baik }\end{array}$ & 61 & 46,9 & 69 & 53,1 & 130 & 100 & \\
\hline Baik & 28 & 15,4 & 154 & 84,6 & 182 & 100 & \\
\hline Total & $\mathbf{8 9}$ & $\mathbf{2 8 , 5}$ & $\mathbf{2 2 3}$ & $\mathbf{7 1 , 5}$ & $\mathbf{3 1 2}$ & $\mathbf{1 0 0}$ & \\
\hline
\end{tabular}

Sumber : Data Primer 2019

Analisa hubungan antara Fungsi afektif keluarga dengan perilaku seksual remaja di SMK negeri 1 manado dengan hasil uji Chi square diperoleh $\rho$ value $=$ $0,000<0,05$. Hal ini menunjukkan terdapat hubungan yang signifikan antara fungsi afektif keluarga dengan perilaku seksual remaja di SMK negeri 1 manado. Hasil penelitian ini, orang tua yang menerapkan fungsi afektif keluarga yang baik memiliki perilaku seksual remaja yang tidak beresiko. Hasil ini sejalan dengan penelitian yang di lakukan oleh Mursafitri, dkk, (2015) dimana terdapat hubungan antara fungsi afektif keluarga dengan perilaku kenakalan remaja. Hal ini juga di dukung oleh penelitian Mellyanika
(2014) yang menyebutkan bahwa salah satu bentuk kenakalan remaja merupakan seperti perilaku seksual.

Manik (2009) mengatakan bahwa kebutuhan responden akan fungsi afektif keluarga tidak jauh berbeda antara responden dengan fungsi afektif keluarga yang adekuat atau yang baik dengan responden yang memiliki fungsi afektif tidak adekuat atau yang kurang baik (Mursafitri, dkk, 2015). Menurut Efendi (2006) fungsi orang tua ialah pendidik. Orang tua merupakan pendidik utama dalam keluarga bagi anak-anak. Hal ini sejalan dengan penelitian oleh Mahardika (2017) yang menyatakan bahwa terdapat hubungan antara peran dari orang tua dengan kejadian perilaku seksual remaja.

Orang tua merupakan subjek pertama yang perilakunya diidentifikasi oleh anak remaja kemudian diinternalisasi yang akhirnya akan menjadi begian kepribadian remaja tersebut (Fitroh, 2016). Keluarga memiliki fungsi penting dalam pembentukan perilaku. Salah satu fungsi keluarga yaitu fungsi afektif, fungsi afektif berguna untuk pemenuhan kebutuhan psikososial. Keberhasilan fungsi afektif tampak melalui keluarga yang gembira dan bahagia. Anggota keluarga mengembangkan gambaran diri yang positif, perasaan yang dimiliki, perasaan yang berarti, dan merupakan sumber kasih sayang (Suarningsih, 2017).

Tabel 7. Hubungan Fungsi Sosialisasi Keluarga dengan Perilaku Seksual Remaja

\begin{tabular}{|c|c|c|c|c|c|c|c|}
\hline \multirow{3}{*}{$\begin{array}{c}\text { Fungsi } \\
\text { Afektif } \\
\text { Keluarga }\end{array}$} & \multicolumn{4}{|c|}{ Perilaku Seksual } & \multirow{2}{*}{\multicolumn{2}{|c|}{ Total }} & \multirow{3}{*}{$\mathbf{P}$} \\
\hline & \multicolumn{2}{|c|}{ Beresiko } & \multicolumn{2}{|c|}{$\begin{array}{c}\text { Tidak } \\
\text { Beresiko }\end{array}$} & & & \\
\hline & $\mathrm{n}$ & $\%$ & $\mathrm{n}$ & $\%$ & $\mathrm{n}$ & $\%$ & \\
\hline $\begin{array}{c}\text { Kurang } \\
\text { Baik }\end{array}$ & 48 & 41,4 & 68 & 58,6 & 116 & 100 & 0,000 \\
\hline Baik & 41 & 20,9 & 155 & 79,1 & 196 & 100 & \\
\hline Total & 89 & 28,5 & 223 & 71,5 & 312 & 100 & \\
\hline
\end{tabular}

Sumber : Data Primer 2019 
Hasil crosstab mengenai hubungan antara fungsi sosialisasi keluarga dengan perilaku seksual remaja di SMK Negeri 1 Manado dengan hasil uji Chi square diperoleh $\rho$ value $=0,000<0,05$. Hal ini menunjukkan terdapat hubungan yang signifikan antara Fungsi sosialisasi keluarga dengan perilaku seksual remaja di SMK Negeri 1 Manado. Hasil penelitian ini, orang tua yang menerapkan fungsi sosialisasi keluarga yang baik memiliki perilaku seksual remaja yang tidak beresiko. Dalam penelitian ini menunjukan bahwa fungsi sosialisasi dari keluarga pada remaja berjalan dengan baik, karena Fungsi Sosialisasi sangat di perlukan bagi para remaja untuk dapat berkomunikasi dengan lingkungan sekitar. Hal ini didukung oleh Sarwono (2006) untuk masalah pergaulan khususnya seksual, remaja cenderung lebih banyak bertanya kepada teman-temannya.

Ketika berinteraksi dengan teman sebaya remaja akan mengenal pergaulan bersama yang kemudian membentuk kelompok-kelompok bersama teman-teman yang mempunyai perilaku atau kebiasaan yang sama (Darmayanti, dkk, 2011). Perilaku seksual remaja sangat dipengaruhi oleh lingkungan teman sebaya, tidak bersifat menetap dan dapat berubah-ubah setiap saat. Untuk itu peranan lingkungan terutama orang tua dan komunikasi dalam melaksanakan fungsi sosialisasi sangat mempengaruhi dalam pembentukan perilaku masa remaja.

\section{SIMPULAN}

Faktor yang sangat mempengaruhi perilaku seksual remaja adalah fungsi afektif keluarga dan fungsi sosialisasi keluarga. Dalam penelitian ini mayoritas responden memiliki fungsi afektif keluarga dan fungsi sosialisasi keluarga yang baik. Dalam penelitian ini, mayoritas remaja memiliki perilaku seksual tidak beresiko.

\section{DAFTAR PUSTAKA}

Ali, Mohammad.,\& Asrori, Muhammad. (2017). Psikologi Remaja.Jakarta :PT Bumi Aksara

Aguma, R. P., \& Dewi, P. A., \& Karim, Darwin. (2014). Hubungan pola asuh orangtua dengan perilaku seksual remaja di sma tri bhakti pekanbaru. Pekanbaru : Program Studi Ilmu Keperawatan. Universitas Riau. https://jom.unri.ac.id/index.php/jo mpsik/article/view/3488

Arinda, R.I. (2014). Hubungan tingkat pelaksanaan fungsi sosialisasi keluarga dengan kemampuan sosialisasi anak usia 4-5 tahun di kb it nurul islam sleman yogyakarta. Program Studi Ilmu Keperawatan STIKES'AISYIYA H. Yogyakarta

Arub, Lathifah. (2017). Hubungan pola asuh orang tua dengan perilaku seksual remaja di smk negeri 1 sewon bantul.Yogyakarta : Universitas Aisyiyah http://digilib.unisayogya.ac.id/2746 /

Badan Kependudukan dan Keluarga Berencana Nasional. (2016). Artikel: fenomena kenakalan remaja di Indonesia.,(http://ntb.bkkbn.go.id.,

Badan Pusat Statistik. (2015). Kemajuan yang tertunda : Analisis data perkawinan usia anak di Indonesia. Berdasarkan Hasil Susenas 20082012 dan Sensus penduduk 2010 https://www.unicef.org/indonesia/i d/Laporan_Perkawinan_Usia_Anak .pdf

Christina, M., Nurmaguphita, D., Rahayu, P. (2017). Hubungan pola asuh orang tua dengan identitas diri pada remaja di smp negeri 1 tempal yogyakarta tahun 2017. UNISA DIGITAL Library-Repository 
e-journal Keperawatan(e-Kp) Volume 7 Nomor 2, Agustus 2019

Darmayanti, Y. Lestari, Y. Ramadani, M. (2011). Peran teman sebaya terhadap perilaku seksual pranikah siswa slta Kota Bukit Tinggi

Departemen Kesehatan Republik Indonesia.(2003).materi pelatihan pelayanan kesehatan peduli remaja. Jakarta Depkes.go.id

Depkes RI. (2015). Situasi kesehatan reproduksi remaja. Depkes.go.id

Dewi, Pristiana Ari. (2012). Hubungan karakteristik remaja, peran teman sebaya, dan paparan pornografi dengan perilaku seksual remaja di kelurahan pasir gubung selatan depok. Thesis Di Publikasikan. Lontar.Ui.Ac.Id/File? File = Digital/ 20297916T30090Ari + Pristiana $+D$ ewi.Pdf

Effendi, M. (2006). Pengantar psikopedagogik anak berkelainan. Jakarta: PT Bumi Aksara

Fitroh, S. F., Khasanah, S. M. (2016). Musik sebagai stimulus pada kecerdasan emosi anak. Program Studi PG-PAUD, Fakultas ilmu pendidikan, Universitas Trunojoyo Madura

Friedman, Marlyn. (2010). Buku Ajar Keperawatan Keluarga Riset, Teori, dan Praktik. Jakarta:EGC

Gultom, O. E., Karyaningsih, E. W. (2015). Hubungan kenakalan remaja dan fungsi sosial keluarga dengan prestasi belajar siswa kelas XI tata boga sekolah menengah kejuruan negeri 4 yogyakarta. Prodi PKK FKIP UST

Gustiani, Y., Ungsianik, T.(2016). Gambaran fungsi afektif keluarga dan perilaku seksual remaja. Fakultas Ilmu Keperawatan UI

Kemendikbud. (2018). Orang tua adalah model pembelajaran bagi anaknya. Kemdikbud.go.id

Kompas.com (Jumat 27 November 2009) Artikel Remaja Australia Ternyata
Lebih Nakal dari Amerika Serikat (https://international.kompas.com/r ead/2009/11/27/17091159. Di akses 13 november 2018

Leni, Saputri. (2019). Hubungan Fungsi Afektif Keluarga Dengan Kecerdasan Emosional Pada Remaja Kelas Xii Sma Negeri 9 Manado.

Mahardika, T. Warsiti. (2017). Hubungan Peran Orang Tua Terhadap Perilaku Seksual Anak Remaja Di Dusus Pasekan Kidul Balecatur Gamping Sleman Yogyakarta

Manik, F., D. (2009). Hubungan pola belajar dengan fungsi afektif keluarga pada mahasiswa reguler angkatan 2008. FK UI

Mellyanika, Dita. (2014). Disfungsi Keluarga Dalam Perilaku Hubungan Seks Pra Nikah Remaja Di Kota Samarinda Kalimantan Timur.

Mursafitri, E., Herlina. Safri. (2015). Hubungan Fungsi Afektif Keluarga Dengan Perilaku Kenakalan Remaja. Program Studi Ilmu Keperawatan Universitas Riau

Mutmainnah. (2013). Analisis Stakeholder Remaja Terhadap Implementasi Program Pelayanan Kesehatan Peduli Remaja PKPR Di Kota Semarang. Fakultas Kesehatan Masyarakat

Notoadmodjo, S. (2010). Metodologi penelitian kesehatan. Jakarta : Rineka Cipta

Nurcholis. (2015). Skripsi Pengaruh Pola Sosialisasi Keluarga terhadap perilaku menyimpang anak. Makasar

Pradhana, Dimas. (2016). Peran Teman Sebaya Terhadap Perilaku Seksual Pranikah Pada Remaja Di Lingkungan Sekolah Menengah Kejuruan Y Di Pacitan 
e-journal Keperawatan(e-Kp) Volume 7 Nomor 2, Agustus 2019

Samsi, W., N. (2012). Peningkatan perilaku asertif terhadap berpacaran melalui pelatihan asertivitas pada siswa kelas $\mathrm{X}$ Pemasan di SMK Negeri 1 Depok. Universitas Negeri Yogyakarta

Santrock, J W. (2007). Remaja (Edisi 11 Jilid 2). Jakarta : Erlangga

Saputri, Novi Dewi. (2015) .Faktor-Faktor Yang Mempengaruhi Perilaku Seks Pranikah Pada Siswi Kelas Xi Smk Muhammadiah 2 Bantul Yogyakarta. Tugas Akhir .Yogyakarya: Universitas Aisyiyah

Sarwono, S. W. (2006). Psikologi remaja. Jakarta: PT Raja Grafindo Perkasa

Sebayang,Wellina., Gultom, Yihana Destyna.,\& Sidabutar,Royani Eva. (2018). Perilaku Seksual Remaja. Yogyakarta : Deepublish

Suarningsih, N. K. A. (2017). Peranan Resilensi Keluarga yang tinggal bersama individu dengan gangguan jiwa.PRODI Keperawatan Fakultas Kedokteran Universitas Udayana

Taukhit, T. (2014).Pengembangan Edukasi Kesehatan Reproduksi Dan Seksualitas Remaja Dengan Metode Game Kognitif Proaktif.Jurnal Studi Pemuda, 3(2) https://jurnal.ugm.ac.id/jurnalpemu da/article/view/32028 